\title{
COVID-19 Pandemic as a Mechanism of the Motion of an Aircraft in MIRCE Mechanics
}

\author{
Jezdimir Knezevic \\ MIRCE Akademy, MIRCE Science Limited, Woodbury Park, Exeter, UK
}

\section{Email address:}

jk@mirceakademy.com

\section{To cite this article:}

Jezdimir Knezevic. COVID-19 Pandemic as a Mechanism of the Motion of an Aircraft in MIRCE Mechanics. American Journal of Engineering and Technology Management. Vol. 6, No. 1, 2021, pp. 1-9. doi: 10.11648/j.ajetm.20210601.11

Received: December 22, 2020; Accepted: January 5, 2021; Published: January 15, 2021

\begin{abstract}
The COVID-19 outbreak has shown that pandemics, like other rarely occurring natural catastrophes, have happened in the past and will happen in the future. Although humans cannot prevent dangerous viruses from emerging, they should be prepared to dampen their consequences for the economy and all of society. The main objective of this paper is to address the COVID-19 pandemic as a novel mechanism of the motion of an aircraft in MIRCE Mechanics, as only then the most effective technological, social and economic actions can be taken by humans to deal with it. Examples of devastating impacts on aviation world-wide are given in the paper, based on available statistics provided by governmental and global commercial aviation associations. Also, examples of professional and technological solutions taken to cushion the impact of COVID-19 on safety in aviation are presented. To assist airlines in the selection process of aircraft types that should be returned to the post pandemic service MIRCE Function ability and Profitability Equations are presented in the paper. However, they are applicable only when the mechanisms of the motion of an industrial system through MIRCE Space are known. As COVID-19 pandemic was not known until the beginning of 2020 business plans of airlines world-wide are for several orders of magnitude off the target, measured in flying hours delivered, revenue generated, an unprecedented number of aircraft grounded and prematurely retirement of B747 and A380 aircraft type from active service. Thus, this paper is bringing together the physiological side of COVID-19 and its physical impact on the operational side of airlines in order to assist them to predict the expected positive and negative work by each aircraft type grounded. This analysis will guide them to decide what type of fleet they should have in the post pandemic times and thus secure the business existence.
\end{abstract}

Keywords: COVID-19, Pandemics, Commercial Aviation, MIRCE Mechanics, MIRCE Function ability Equation, MIRCE Profitability Equation, Vaccine, Vaccination

\section{Introduction}

The philosophy of MIRCE Science is based on the premise that the purpose of existence of any industrial system is to be industrial ${ }^{1}$, which means doing the expected work. The work is considered to be done when measurable functionality (function, performance and attributes) is delivered through time, like annual miles travelled, monthly units produced, daily energy supplied and similar. [1]

According to MIRCE Science, at any instant of calendar time, any industrial system could be in one of the following

1 Industrial, adj - from Medieval Latin industrialis, in relation to Latin industria meaning "engaged in, for use in, serving the needs of industries". two industrial states:

Positive Industrial State (PIS), a generic name for a state in which an industrial system is doing work,

Negative Industrial State (NIS), a generic name for a state in which an industrial system is not doing work.

In MIRCE Science a work done by an industrial system is uniquely defined by the trajectory it traces thorough MIRCE Space. Mathematically, it is a continuous three-dimensional space containing discrete points, each representing an industrial state that an industrial system could be found in at any instant of time and the corresponding probabilities.

The motion of an industrial system through industrial states is governed by the following two types of actions:

Negative Industrial Action (NIA) that causes occurrences 
of negative industrial events (NIE) at which industrial systems are compelled to move to NIS.

Positive Industrial Action (PIA) that causes occurrences of positive industrial events (PIE) at which industrial systems are compelled to move to PIS.

MIRCE Mechanics is a part of MIRCE Science that focuses on the scientific understanding of the mechanisms that generate positive and negative industrial actions, which uniquely define a time evolution of industrial systems though MIRCE Space. [1] The minimum sufficient "physical scale" that enables scientific understanding of the mechanisms that govern positive and negative actions is between $10^{-10}$ of a metre (the level of the atoms) and $10^{+10}$ of a metre (at the level of the solar system). A full understanding of these mechanisms is essential for the predictions of expected performance of industrial systems using MIRCE Science Equations, like works done and resources consumed.

\section{COVID-19 Pandemic}

According to the World Health Organisation (WHO) a pandemic is "the world-wide spread of a new disease", which is infectious and contagious.

As humans learned to live in-groups forming communities where they live close to each other and also travel across the seas, numerous diseases have spread around the world. Throughout history there have been numerous pandemics that claimed the lives of thousands, even millions of people. The top ten pandemics that affected humanity are presented in Table $1^{2}$.

Table 1. Top ten pandemics throughout the human history.

\begin{tabular}{ll}
\hline Pandemic & Duration \\
\hline Antonine Plague & $165-180$ \\
The Black Death & $1347-1352$ \\
Small Pox Pandemic & $1870-1874$ \\
Cholera & $1817-1824$ \\
Russian Flu & $1889-1890$ \\
Spanish Flu & $1918-1919$ \\
H3N2 Pandemic & $1968-1970$ \\
HIV/AIDS & $1981-?$ \\
SARS & $2002-2004$ \\
COVID-19 Pandemic & $2019-$ current \\
\hline
\end{tabular}

The global pandemic caused by the newly discovered severe acute respiratory syndrome coronavirus 2 (SARSCoV-2) has caused world-wide suffering and death of unimaginable magnitude from coronavirus disease 2019 (COVID-19). As the patient volume escalated, health systems stalled and the authorities rushed to fire fighting. Appeals for staying at home, washing hands, and helping in "flattening the curve" filled public discourse. The WHO contributed to the confusion for it could not determine until the last week in January 2020 whether the human-to-human transmission was possible. Moreover, in public communication, the WHO did

2https://www.worldatlas.com/articles/10-pandemics-throughout-history.html (accessed 23.11.2020) not label the virus with "SARS" allegedly in order to avoid a mass panic. This move could have muted the alarm and bolstered the flu believers as well as deniers of the COVID19 threat. [2]

The effects from the SARS-CoV-2 crisis on human health, health care systems and the global economy have been profound. The major cause of mortality from COVID-19 is acute respiratory failure from acute respiratory distress syndrome (ARDS), although a number of patients with the disease are showing cardiovascular issues such as congestive heart failure, cardiac arrhythmias and vascular thrombosis, as well as brain dysfunction. [3]

In order to make copies of themselves viruses must enter the cells of their hosts, which can be humans, copies are then released by the host cells and enter into circulation in the body, infecting still more cells. Then propagate through the world via host emissions such as respiratory droplets and infect new people. [4]

Transmission of respiratory infections such as COVID-19 is primarily via virus-laden fluid particles (i.e. droplets and aerosols) that are formed in the respiratory tract of an infected person and expelled from the mouth and nose during breathing, talking, coughing and sneezing. Droplets larger than a critical size settle faster than they evaporate, and so contaminate surrounding surfaces. [5]

Droplets smaller than this size evaporate faster than they settle, so forming droplet nuclei that can stay airborne for hours and may be transported over long distances.

Human-to-human transmission of COVID-19 occurs primarily via three routes:

large droplets that are expelled with sufficient momentum so as to directly impact the recipients' mouth, nose or conjunctiva;

physical contact with droplets deposited on a surface and subsequent transfer to the recipient's respiratory mucous;

inhalation by the recipient of aerosolised droplet nuclei from the expiratory ejecta that are delivered by ambient air currents.

The first two routes associated with large droplets are referred to as the 'droplet' and 'contact' routes of transmission, whereas the third is the so-called 'airborne' transmission route. Respiratory infections hijack our respiratory apparatus to increase the frequency and intensity of expiratory events, such as coughing and sneezing, which are particularly effective in generating and dispersing viruscarrying droplets. [5]

Today, by using predictive, physics-based modelling software biophysics has made huge advances towards the race for funding a vaccine for COVID-19. [6]

\section{Impact of COVID-19 on Aviation}

At the beginning of the 2020 the world's airlines were operating around 24,000 passenger jets with at least 50 seats. Today that number is lower by approximately $80 \%$. The impact of COVID-19 on UK passenger air transport movements is drastically reduced, as shown in Figure 1 [12]. 


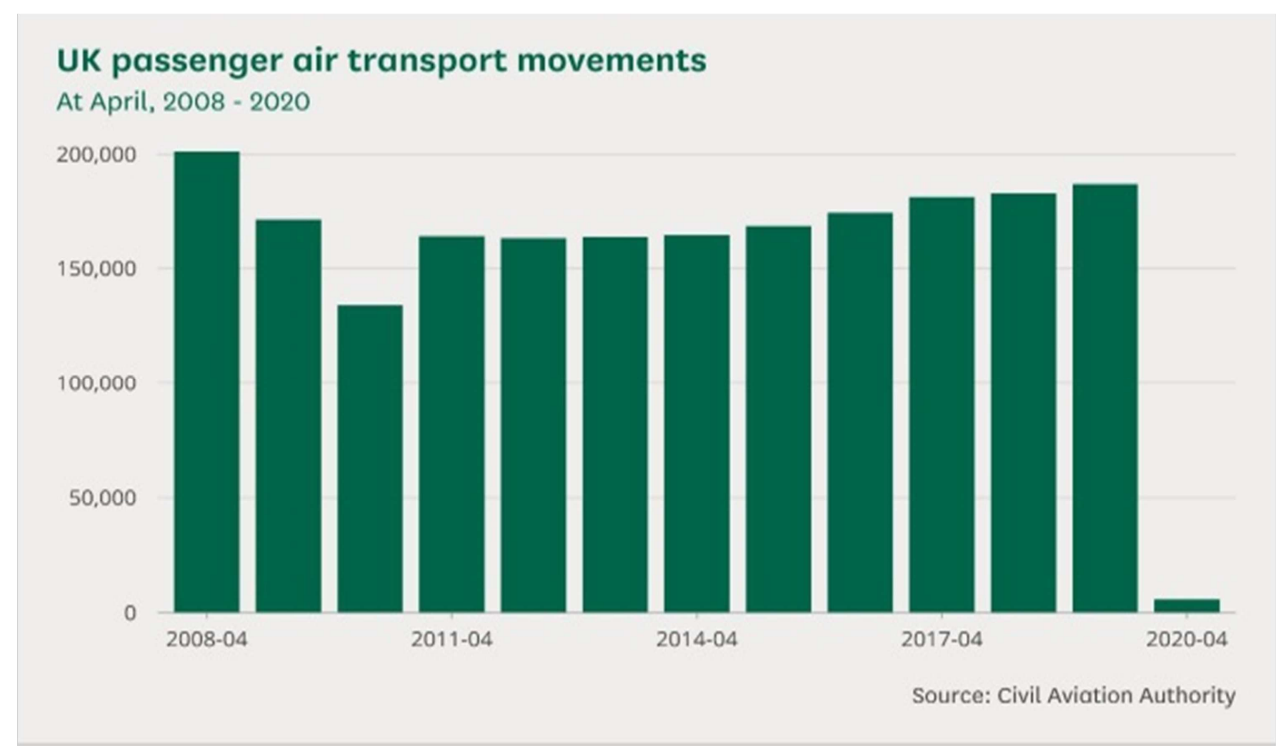

Figure 1. UK passenger air transport movements.

The drastic reductions of flights in commercial aviation happened in the past due to some of the following negative mechanisms that generated NIE:

design problems:

grounding of Boeing B737 MAX by aviation safety authorities world-wide, following two fatal accidents that involved the plane's anti-stall system,

grounding of Rolls Royce Trent 1000-powered aircraft (B787) due to cracking problems in the intermediate pressure section of the turbine,

grounding of Concord after the crash outside Paris in which 113 people died.

natural phenomena: volcano eruptions, earthquakes, fires, bird strikes and similar,

weather conditions: tornadoes, hurricanes, blizzards, fog, and floods,

political situations: wars and economical embargoes.

The commonality in all of the above mentioned cases is the fact that there have been demands for work done by airlines (delivery of commercial flights), but they could not deliver the expected work (flights) due to safety and reliability reasons. However, the drastic reduction in the number of global commercial flights in 2020 is due to a totally different reason. Airlines and their fleets are in positive industrial state ready to deliver safe and reliable flights, but there is no demand for flights by the flying public, due to the fear of the further spread of COVID-19, by individuals, health and other governmental organisations.

Although humans cannot prevent dangerous viruses from emerging, they should be prepared to dampen their consequences for the economy and all of society. The main objective of this paper is to address the severe impacts of COVID-19 on the commercial aviation across the globe and to present the best technological, social and economical actions taken by humans to deal with it. Examples of devastating impacts on aviation and transportation industries are given in the paper, as well as, the human and technological measures taken to cushion their consequences.

\section{COVID-19 Pandemic Generated Negative Industrial Events in Aviation}

Aircraft are designed in accordance to the laws of science and engineering to transport humans and cargo between chosen destinations through the air. Given satisfactory weather conditions, each airworthy aircraft is in a PIS, which means it is able to safely and reliability deliver expected transpiration work.

The business plan of each airline, world wide, expect that each aircraft in their fleet will safely and reliably deliver between 3500 and 4500 flying hours per calendar year. Hence, the types of aircraft in their fleets are determined by their ability to attract passengers on the routes chosen to fly. All of these factors together determine the price of each ticket, in the way that the revenue generated by flying passengers and cargo is greater than the cost of the resources associated with a delivery of the business plan.

From the beginning of 2020 the Covid-19 pandemic caused havoc in each airline, as their respective aircraft are not delivering flights in accordance to the business plan. By the end of 2020 it became clear that no airline in the world had managed to deliver the expected flying hours from their airworthy aircraft. The end of the year business reports will reveal the final statistics, but the estimated revenue loss, due to the outbreak of COVID-19, for the first six months of 2020 is around $\$ 314$ billion $^{3}$.

The remaining part of the paper will examine the causes of

3https://www.inaa.org/covid-19-economic-impact-of-pandemics-onaviation/\#: :text=Covid-

19\%3A\%20Economic\%20Impact\%20of\%20Pandemics\%20on\%20Aviation \%20J uly,firing $\% 20$ line $\% 20 \mathrm{of} \% 20 \mathrm{a} \% 20$ potentially $\% 20$ devastating $\% 20$ financial $\% 20 \mathrm{cri}$ sis. (accessed 6.12.2020). 
those losses as well as the measures that the global aviation has taken to deal with the totally new business reality.

\subsection{Impact of the COVID-19 Pandemic on Flight Safety}

Although the global reduction in commercial air travel, due to the Covid-19 pandemic, has in many ways eased pressure on commercial aviation, in some cases it had the opposite effect on safety. The drastic drop in airline passengers has triggered an unusual type of incidents that are affecting flight safety, according to publicly available reports as well as government, industry and union officials ${ }^{4}$.

Details of incidents have begun to trickle out through NASA's Aviation Safety Reporting System ${ }^{5}$ (ASRS), which posts anonymous field reports after validating their authenticity. They include pilots reporting that:

unusually light airliners behaved unexpectedly, such as climbing so fast that they exceeded assigned altitudes or couldn't maintain cabin air pressure.

one nearly empty passenger jet, according to the crew "climbed like a rocket," prompting them to exceed their assigned altitude

some aircraft have scraped their tails on takeoff,

some have gone off course or strayed close enough to other aircraft to prompt mid-air collision alerts

the boarding process went so fast that the crew forgot to finish safety paperwork

normal flight routines are being disrupted as thousands of airliners are parked, some of them on runways at major airports.

\subsection{Impact of the COVID-19 Pandemic on Existing Aircraft Cleaning Procedures}

As a result of the COVID-19 pandemic after each landing each airworthy aircraft moves to NIS. This is due to health and safety risks, as it is possible that the residual COVID-19 droplets on the accessible surfaces in the aircraft cabin, including the toilets, could infect passengers boarding it for the next flight. [6]

Aircraft manufacturers have published procedures on how to clean aircraft and what products to use for years. Events such as SARS and the current COVID-19 pandemic have prompted them to issue reminders and, as lessons are learned, provide updates. However, an Airline Pilots Association report issued in spring of this year cited reports of noncompliance at 16 U.S. carriers and one in Canada. Most of the issues concern the frequency and thoroughness of the aircraft-interior disinfecting and the materials being used [7]. For example, pilots have been provided with hand wipes that are not on the Environmental Protection Agency's E-list, which tracks products known to work against the novel coronavirus.

In the US the FAA and other regulators are hesitant to

4 Alan Levin, Bloomberg, June 12, 2020

5 https://asrs.arc.nasa.gov/report/caveat.html?formType=general\#: :text=NASA $\%$ 20has $\% 20$ established $\% 20$ an $\% 20$ Aviation $\% 20$ Safety $\% 20$ Reporting $\% 20$ System, de scribed\%20in\%20detail\%20in\%20FAA\%20Advisory\%20Circular\%2000-46E. mandate aircraft-cleaning protocols, referring instead to health agency guidance, which focuses largely on aircraft cabins. Instructions on cleaning flight decks, such as in the International Civil Aviation Organisation guidance on protecting cargo pilots issued on 11 May 2020, refer to manufacturers' recommendations.

A pilot for an unnamed airline filed a ASRS report in spring 2020 detailing an onboard smoke event. "[An] air carrier captain reported smelling a burning smell during cruise," the report's summary says. "Post-flight maintenance briefing advised the pilots that alcohol from wipes may be shorting out wires." The unnamed airline reported that the issue had turned up on "several" aircraft.

Despite not enforcing social distancing while seated, United Airlines is committed to ensuring its planes are cleaned thoroughly between flights. The airline recently extended its cleaning procedures to include robots. The robots will spray antibacterial liquid over all the surfaces that passengers touch. This includes the toilets and the tray tables, as well as, overhead bins, seats, armrests and overhead air filters [8]. This deep clean will not be used in between each flight, but on a weekly base.

The Occupational Safety and Health Administration's (OSHA) General Duty Clause requires employers to provide a workplace free from recognised hazards likely to cause death or serious physical harm, under which COVID-19 would fall. For many employees, aircraft is their workplace. Hence, it is the mission of any fleet manager to lower the probability of potential infections among those using fleet assets and to minimise the risk of spreading the virus to others with whom they interact. Although the virus is primarily spread via person-to-person contact; it is also possible to be infected by touching a surface, that has living COVID-19 virus on it and then touching mouth, nose, or eyes. A comprehensive list of policies and procedures designed to minimise COVID-19 contagion in a fleet is given in Antich [9].

\subsection{Impact of the COVID-19 Pandemic on Usage of Toilets on Commercial Flights}

Since the creation of the multi class cabin, passengers are allowed to use toilets in their ticketed determined cabin only. However, starting from 1 November 2020, based on feedback from both passengers and crew, United Airlines has changed this policy. Hence, passengers are allowed to use the first class toilets, regardless of which class tickets they are travelling, as a way to reduce queuing and crowding around toilets. Although the cabin crew advise the passengers to "use the restroom located in your cabin when possible", when there is overcrowding of one toilet passengers can move around the cabin to use a different toilet, even if it means passing from economy into first class ${ }^{6}$. The altered policy allows flight attendants more flexibility to let customers use another toilet during certain situations. That may include when there is a line for one toilet but not another, when the

6 https://simpleflying.com/united-airlines-first-class-toilet/?utm_source=Bibblio 
service cart is in the aisle, etc.

Other airlines such as American have long allowed passengers to use whichever toilet they choose. However, a Delta airline restricts passengers to the toilet in their class.

\subsection{Impact of the COVID-19 Pandemic on Personal Protection Equipment for Chinese Cabin Crew}

The Civil Aviation Administration of China (CAAC), in its latest edition of Technical Guidelines for Epidemic Prevention and Control for Airlines, are suggesting cabin crew wear disposable diapers. The advice is meant to limit the use of toilets while flying to and from high-risk destinations $^{7}$. The 38-page document contains special recommendations for charter flights to and from regions where infections exceed 500 in every one million people. They include, among other things, goggles, disposable shoe covers and nappies.

The Personal Protection Equipment (PPE) recommendations also list surgical masks, double-layer disposable gloves, goggles, disposable caps, disposable protective clothing, and disposable shoe covers. Cockpit crew should also wear masks and goggles but are exempt from the nappy request.

The CAAC advises that the last three rows of the cabin on high-risk flights be designated as an emergency quarantine area. The document also requires the airline to divide the rest of the cabin into sections, which include a "clean area," a buffer zone, and a passenger sitting area, each of which are to be divided by disposable curtains.

Chinese domestic aviation has made a remarkable recovery. It is already back to near-full capacity from 2019. On December 9th, the entire country of 1.39 billion people recorded only 12 new coronavirus cases. Its economy appears to have succeeded in creating the much-desired Vshaped recovery more optimistic projections had been foreseen at the beginning of the crisis.

\subsection{Impact of the COVID-19 Pandemic on the Decisions of Where to Ground Aircraft}

When bookings collapsed for fear of coronavirus, airlines world wide, grounded majority of their aircraft. Hasty grounding meant that only a few of the more than 700 locations where aircraft are now stored were designed for longterm storage. The Mitiga Meteorological and Aerosol Contaminants Index ${ }^{8}$ assesses many airports where aircraft are now stored as high in corrosion risk, extreme in temperatures, or contaminated with sea salt, dust or sulphur dioxide. Singapore and Jakarta are especially bad for stored aircraft.

However, there is a trade-off in grounding decisions. Airport storage costs more and has higher risk of damage from unfavourable environments, but it enables airline mechanics to perform the storage maintenance. In contrast, desert or dry-region storage cost less and is better for aircraft,

7 https://simpleflying.com/chinese-cabin-crew-nappies/(accessed 23.12.2020)

8 https://www.twu557.org/index.php/10-latest-news/579-aw-mro-online-toughdecisions-on-grounded-ac but requires ferry costs and expenses for contractors for executing required maintenance tasks.

It is necessary to stress that storage also poses technical challenges, like: updating software in remote locations, implementation of time-limited tasks and $\mathrm{ADs}^{9}$.

When the aircraft is in PIS, but in passive mode, it still has to be maintained. It is necessary to rotate the tires, to rotate the engines, check all the fluids, the oils, and all the lubricants. So obviously, all of these maintenance events will continue to be accomplished, as part of the business of an airline.

OEMs have been working with airlines to find efficient ways of doing maintenance on grounded jets, keeping them safe while saving man-hours. They are addressing calendartime tasks and looking for opportunities to combine tasks.

\subsection{Impact of the COVID-19 Pandemic on the Contamination of Fuel and Fuel Tanks in Grounded Aircraft}

In the COVID-19 pandemic environment thousands of aircraft are parked and the probability of fuel contamination is higher than normal. Fuel microbes thrive in heat and humidity, and if fuel becomes contaminated it can corrode fuel tanks and cause wing structure damage. Hence, the fuel testing must be carried out more frequently in the current circumstances, especially on those aircraft standing idle in hot and humid places. [2]

Aircraft in tropical areas, much of Latin America, Africa, the Middle East, Southeast Asia and Australasia, are considered to be at higher risk of microbiological contamination, according to the International Air Transport Association (IATA). Tests that used to be done at least once per year now need to be done about every other week, according to Conidia Bioscience corporation ${ }^{10}$, which develops fuel tests for various industries. In addition to increased testing, operators are ramping-up fuel tank borescope or visual inspections for aircraft in a temporary parked situation.

While operators or maintenance organisations run a grounded aircraft to make sure the systems are working, the aircraft uses some fuel. This can leave residue in the tanks, which can cause problems. Any moisture in the fuel tank, due to heat or humidity, can cause contamination, The fungi has the ability to stick to the tank, so even if the fuel is free of contamination, parked aircraft in hot or humid areas face increased microbial contamination, which requires extra inspections.

EasyJet has increased testing from once per year to once every 14 days, and the airline is testing in 21 locations instead of one. For many operators, the more frequent testing means more samples to be send the laboratory, which is

\footnotetext{
9 An airworthiness directive (commonly abbreviated as AD) is a notification to owners and operators of certified aircraft that a known safety deficiency with a particular model of aircraft, engine, avionics or other system exists and must be corrected.

10 https://conidia.com/industries/aviation/.
} 
where many test providers still process samples. To take fuel test samples, send them to labs, and wait for the results ordinarily takes 4-10 days. Today, when aircraft are scattered around airfields away from home bases, the process inevitably takes longer and requires more resources.

As the duration of the COVID-19 pandemic is unknown, ultimately the point could be reached where de-fuelling is required, especially if it's for disposal because it's been contaminated. In those cases some additional maintenance actions will be required because disposal of contaminated fuel is not something that is routinely done at airports. [3] The logistics of this process is rather challenging regarding the availability of injection carts, availability of the additive, and also simple things like being able to access aircraft that are parked nose to tail on taxiways.

\section{Impact of the COVID-19 Pandemic on the Aircraft Type Retirement}

The current pandemic has severely impacted international travel demand, particularly the large-cabin segment of the market. Figure $2^{11}$ clearly illustrates the drastic drop in the daily flying hours of the two "sky giants".

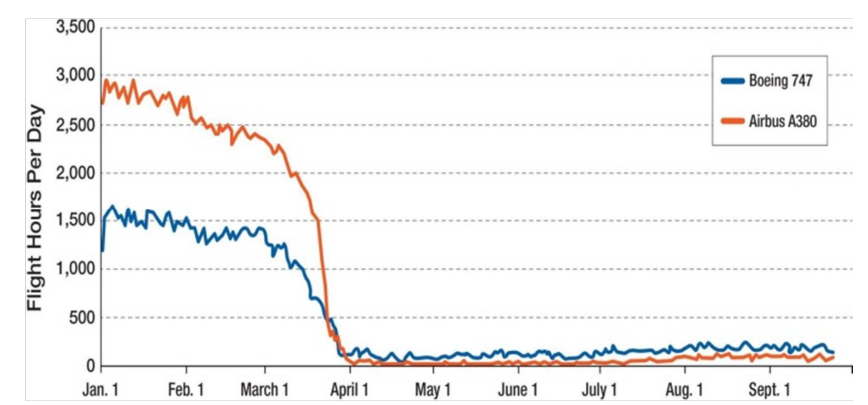

Figure 2. Daily flights hours of $A 380$ and B747 during the first 9 months of 2020

\subsection{Impact of the COVID-19 Pandemic on the Retirement of $A 380$}

The A380, as the world's largest commercial passenger aircraft, has been more negatively impacted than any other type, with several national flag carriers recently announcing full retirements of their A380 fleets.

In the context of the current COVID-19 crisis and its impact on anticipated activity levels, the Air France-KLM group announces today the definitive end of Air France Airbus A380 operations. The group had previously planned to phase out its super-jumbo fleet by the end of 2022 as part of a broader strategy of rationalising and simplifying its fleet in a bid to improve effectiveness and reduce cost. Air France, the first European airline to operate the A380 retired its last one in June 2020, having once operated as many as 10 . The overall impact of the A380 phase-out amounts to a writedown of $€ 500$ million and the group said that would be booked in the second quarter of 2020 as a non-current

11 Source: Aviation Week Fleet Discovery, Commercial passenger aircraft only. cost/expense. Air France said A350s and Boeing 787s would replace the A380s.

Lufthansa, which has already offloaded half its 14 A380s, does not expect to fly the remaining airframes until at least 2022 and meanwhile will keep them in deep storage.

Outside of Europe, the future of the aircraft in the fleets of Etihad, Qatar Airways and Thai Airways has also been the subject of discussion since the COVID-19 outbreak.

The early retirement of the A380 type of aircraft is a totally unexpected development for the commercial aviation community, starting with the designers, manufactures and operators. Normally, all significant design decisions are made on the expectation that each aircraft type will stay in operation for 25 years. Hence, all design compromises, between mutually competing engineering and management decisions are based on around $80 \%$ occupancy rate per flight over the life span of 25 years. Certainly, this is far from the COVID-19 impacted destiny of A380, which entered into service only in 2007 and as of May 2020, according to Airbus, there were approximately 228 of the aircraft in service with 14 operators.

\subsection{Impact of COVID-19 Pandemic on the Retirement of B747}

The future life of the B747, also known as the "Queen of the Skies" is similar to that of the A380. British Airways is one of the world's largest users of the Boeing 747, receiving its first Boeing 747-100 in 1971. The latest version, the B747-400, was delivered in 1989.

On 17 July British Airways announced the immediate early retirement of their fleet of 30 Boeing 747-400s. The aircraft had been due to retire gradually over the next few years, with the last planes exiting the company by 2024 . However, no more commercial flights are expected now for the airline's fleet of Boeing $747 \mathrm{~s}$, subject to consultation with the relevant unions.

In the communication to staff, British Airways said, "They are an airliner of another era, however, and they burn far more fuel than the latest generation of planes and, logically, require more frequent and detailed attention from our engineering team. They rely on high passenger load factors and high premium demand to make them commercially viable. Subject to proper consultation, their early retirement would be accelerated over the coming months, and we would not expect any more commercial flights.. The proposal to retire the entire fleet of these iconic aircraft is nothing short of heartbreaking for those of us that grew up watching them fly all over the world."

The exit of the aircraft will affect hundreds of British Airways pilots that are only qualified to fly the aircraft specifically.

\section{Use of MIRCE Science Equations for the Post the COVID-19 Fleet Selection}

When bookings collapsed for fear of coronavirus 
grounding aircraft was a painful, but easy business decision for airlines. However, when the recovery begins, airlines must decide ${ }^{12}$ :

which and how many aircraft to put back into service immediately,

how to get them back most economically,

where and how to store the aircraft not needed soon,

which aircraft to retire and how to gain the most value out of it.

Answers to the above listed questions are rather complex, as there are many factors that need to be considered under the veil of uncertainties. A common guess is that no more than 5,000 of the currently parked aircraft will return to service by the end of 2021. That would leave more than 8,000 aircraft to find more permanent homes than the cold or humid airports.

MIRCE Science Equations are mathematical expressions of the motion of industrial systems through MIRCE Space, developed by Knezevic [1]. They enable predictions of the expected work to be done by operationally defined industrial system, together with resources required, which when converted into monetary values present the expected cost and revenue, from the birth of the system to its retirement.

\subsection{MIRCE Functionability Equation}

According to the MIRCE Science the probability of an industrial system being in PIS, at a given instant of time $t$, is defined by the MIRCE Functionability Equation, originated by Knezevic [10], thus:

$$
y(t)=P(P I S, t)=\sum_{i=1}^{\infty} P\left(P I S^{i}, t\right)=\sum_{i=1}^{\infty}\left[O^{i-1}(t)-F^{i}(t)\right]
$$

where:

$$
O^{i}(t)=P\left(T P E^{i} \leq t\right)
$$

is the probability that the time to $i^{\text {th }}$ PIE will take place between the birth of a system and a given instant of time $t$

$$
F^{i}(t)=P\left(T N E^{i} \leq t\right)
$$

is the probability that the time to $\mathrm{i}^{\text {th }}$ NIE will take place between the birth of a system and a given instant of time $t$.

The positive work done, PW(T), by an industrial system during the stated interval of time $\mathrm{T}$, can be calculated by making use of the following expression:

$$
P W(T)=\int_{0}^{T} y(t) d t
$$

The numerical value of the above expression, when applied to each operationally defined aircraft type, presents the amount of time it is expected to be in PIS delivering flying hours and generating revenue.

12 https://www.twu557.org/index.php/10-latest-news/579-aw-mro-online-toughdecisions-on-grounded-ac (accessed 1.12.2020).
Correspondingly, the negative work done, NW(T), by a given aircraft type, presents the amount of time it is expected to be in NIS consuming: maintenance man-hours, storage hours and necessary resources (material, facilities, energy, equipment and similar) during the stated interval of time $\mathrm{T}$, can be calculated by making a use of the following expression:

$$
N W(T)=\int_{0}^{T} n(t) d t
$$

Where

$$
n(t)=P(N I S, t)=\sum_{i=1}^{\infty}\left[F^{i}(t)-O^{i}(t)\right]
$$

\subsection{MIRCE Profitability Equation}

The creation of the MIRCE Functionability Equation enabled the development of the MIRCE Profitability Equation developed by Knezevic [11] that links the revenue and cost sides of business, by integrating the consequences of system engineering decisions, adopted business methods and project management decisions.

According to MIRCE Science, the expected revenue of a given industrial system, during the stated interval of time, $\operatorname{Rev}(T)$, expressed in the monetary units (MU), is equal to the product of the Hourly Income generated by the provision of business function, $\mathrm{HI}$ and the amount of the work done by the system, thus:

$$
\operatorname{Re} v(T)=H I \times P W(T) \quad[M U]
$$

In general terms, the cost of doing positive work during the stated period of time ${ }^{13}, \mathrm{CPW}(\mathrm{T})$, which is equal to the sum of the fix cost, $C P W_{f i x}(T)$ and variable cost that is equal to the product of the Hourly Cost of positive work, $H C_{P W}$ and the duration of the time an industrial system spends in PIS, thus:

$$
C P W(T)=C P W_{f i x}(T)+H C_{P W} \times P W(T) \quad[M U]
$$

Equivalent cost for doing negative work (maintenance and storage), during the stated period of time ${ }^{14}, \mathrm{CNW}(\mathrm{T})$, which is equal to the sum of the fixed cost, $C N W_{f i x}(T)$ and variable cost that is equal to the product of the Hourly Cost of negative work, $\mathrm{HC}_{\mathrm{NW}}$ and the duration of the time an industrial system spends in NIS, thus:

$$
C N W(T)=C N W_{f i x}(T)+H C_{N W} \times N W(T)
$$

\footnotetext{
13 Monetary value of resources used for the execution of all tasks needed for doing positive work, like: personnel, material, facilities, equipment, energy, information and so forth.

14 Monetary value of resources used for the execution of all tasks needed for doing negative work, like: personnel, material, facilities, equipment, energy, information and so forth.
} 
Finally, the profit expected to be generated by a given industrial system, during the stated period of time, PROFIT(T), could be calculated by making use of the MIRCE Profitability Equation, thus:

$$
\begin{aligned}
& \operatorname{PROFIT}(T)=\operatorname{Re} v(T)-C(T) \\
& \quad=H I \times P W(T)-[C P W(T)+C N W(T)] \quad[M U]
\end{aligned}
$$

In summary the above equation is the only one, known to the author, which unifies all aspects of the existence of an industrial system. It enables the accurate predictions of the expected profit to be made for each operational scenario, maintenance policy and support strategy. Thus, MIRCE Science unites the whole organisation into an analytical scheme, rather than being a collection of a large number of self standing models that address a few components at a time, or a few performance parameters of the system alone.

It is necessary to stress that the above-presented equations are applicable only when the mechanisms of the motion of an industrial system through MIRCE Space are known. COVID19 is one of those that were not known until the beginning of 2020. Consequently business plans of airlines world-wide are for several orders of magnitude off the target, measured in flying hours delivered, revenue generated, number of aircraft grounded and those retired from active service.

\section{COVID-19 Pandemic Generated Positive Industrial Events in Aviation}

In commercial aviation repairs, replacements, modifications and similar maintenance actions are the most frequently used PIA to return an aircraft in PFS. However, in current situation when majority of world existing commercial aircraft are grounded vaccination is the only positive action that will return them to the sky. Vaccination is a 'miracle of modern medicine' and the most important contribution to public health in the past 100 years. From 1796, when the first vaccine was introduced to protect a global pollution from smallpox, vaccination was the main weapon for protecting humans against pneumonia, measles and countless other infections. [13] The value of vaccination has once again been emphasised with the outbreak of COVID-19. No scientific breakthrough is ever more eagerly anticipated than this one. Considerable scientific resources and billions of pounds have been placed on producing an effective vaccine to "offset" hundreds of thousands of lives lost and millions of flying miles were not delivered due to nearly total grounding of global commercial aircraft.

It is necessary to stress that developing the vaccine is only a part of the challenge; it is vaccination not just the vaccine that saves lives, which means ensuring that enough individuals are vaccinated is the imperative. [14] A recent survey conducted shown that around $36 \%$ in the UK and 51\% in the US report they are either uncertain or unlikely to be vaccinated against COVID-19. [15] Thus, convincing the general public that the vaccine is safe is another positive action regarding the motion of an aircraft through MIRCE Space.

\section{Conclusions}

The main objective of this paper is to address the impact of the COVID-19 pandemic as a mechanism of the motion of an aircraft though MIRCE Space, which is a mathematical reality of the observed physical realities, experienced in aviation world during 2020.

The COVID-19 outbreak has shown that pandemics, like other rarely occurring natural catastrophes, have happened in the past and will happen in the future. Although humans cannot prevent dangerous viruses from emerging, they should be prepared to dampen their consequences for the economy and all of society.

Examples of devastating impacts on aviation world-wide are given in the paper, as well as, some of the human and technological solutions taken to cushion their consequences.

To assist airlines in the selection process of aircraft types that should be returned to the post pandemic service MIRCE Functionability and Profitability Equations are presented in the paper. They embrace the impact of COVID-19 on the expected positive and negative work, as well as the cost of associated resources, which determine their business existence. However, the above-presented equations are applicable only when the mechanisms of the motion of an industrial system through MIRCE Space are known. As COVID-19 pandemic was not known until the beginning of 2020 business plans of airlines world-wide are for several orders of magnitude off the target, measured in flying hours delivered, revenue generated, number of aircraft grounded and those retired from active service.

\section{Acknowledgements}

The author wishes to thank the American Journal of Engineering and Technology Management for support regarding the publishing of this paper.

\section{References}

[1] Knezevic, J., The Origin of MIRCE Science, pp 242, MIRCE Science, Exeter, UK, 2017. ISBN 978-1-904848-06-6.

[2] Travica, B., COVID-19 Pandemic Global View: Containment Efforts and Implications, paper 14, Virtual 30th MIRCE International Symposium, MIRCE Akademy, Exeter, UK, 15 December 2020 (www.mirceakademy.com).

[3] Knezevic. J., Microbial Decontamination of Fuel Tanks as a Mechanism of the Motion of an Aircraft through MIRCE Space.ABEB.MS.ID.000598.1033552/ABEB.2020.04.000598.

[4] Hosoki, K., Chakraborty, A., SanjivSur, S., Molecular mechanisms and epidemiology of COVID-19 from an allergist's perspective, Journal of Allergy and Clinical Immunology, Vol. 146, Issue 2, pp. 285-299, August, 2020. 
[5] Bohn, M. K., Hall, A., Sepiashvili, L., Jung, B., Steele, S., Adeli, K., Pathophysiology of COVID-19: Mechanisms Underlying Disease Severity and Progression, Molecular Medicine, Research Institute, The Hospital for Sick Children, University of Toronto, Toronto, Ontario, Canada.

[6] Goupil-Lamy, A., Virus mechanism: How visualising COVID19 molecular structure helps to understand its vulnerabilities, Dassault Systemes, COMAPSS 3Dexperience Magazine, 20 October 2020.

[7] Mittal, R., Ni, R., Jung-Hee, S., The Flow Physics of COVID19, J. Fluid Mech. (2020), vol. 894.

[8] Veillette, P., Flying Petri Dish: Aircraft Can Accelerate The Spread Of Disease, Aviation Weekly, Washington D.C., USA.

[9] Antich, M., Fleet Policies \& Procedures to Minimise COVID19 Contagion, Automotive Fleet, March 23, 2020, USA.

[10] Knezevic, J., Int. Journal of Engineering Research and Applications, ISSN: 2248-9622, Vol. 4, Issue 8 (Version 7), August 2014, pp.93-100.
[11] Knezevic, J., Mašinstvo - Journal of Mechanical Engineering, Vol. (13), No. 2, 115-122, (2016), Zenica, Bosnia and Hercegovina.

[12] The Impact of the Coronavirus Pandemic on the Aviation Sector, House of Commons Transport Committee, British Government, London, UK, 2020.

[13] Anderson RM. 2016 The Impact of Vaccination on the Epidemiology of Infectious Diseases. In The Vaccine Book, pp. 3-31 Elsevier. (doi: 10.1016/b978-0-12-802174-3.00001$1)$.

[14] Ehreth J. 2003 The value of vaccination: a global perspective. Vaccine 21, 4105-4117 (doi: 10.1016/s0264-410x(03)00377$3)$.

[15] Covid-19 Vaccine Deployment: behavior, ethics, misinformation and policy strategies, The Royal Society, London, UK, 21 October 2020. 